\title{
Building Information Modeling (BIM): Exploring Level of Development (LOD) in Construction Projects
}

\author{
Aryani Ahmad Latiffi ${ }^{1, \text { a }}$, Juliana Brahim ${ }^{2, b}$, Suzila Mohd ${ }^{3, c}$ \\ and Mohamad Syazli Fathi ${ }^{4, d}$ \\ 1,2,3 Department of Construction Management, Faculty of Technology Management and Business, \\ Universiti Tun Hussein Onn Malaysia (UTHM), 86400 Parit Raja, Batu Pahat, Johor, Malaysia \\ ${ }^{4}$ UTM Razak School of Engineering and Advanced Technology, Universiti Teknologi Malaysia \\ (UTM), 54100 Kuala Lumpur, Malaysia \\ aaryani@uthm.edu.my, bju_brahim@yahoo.com, csuzilamohd@gmail.com, d'syazli@utm.my
}

Keywords: Building Information Modeling (BIM), Level of Development (LOD), Public Sector, Private Sector, Malaysian Construction Industry

\begin{abstract}
Level of Development (LOD) is a protocol to address the basic guidelines information of Building Information Modeling (BIM). LOD is created to identify specific content requirements of a BIM model elements at a given time. It is used to reduce the problem of inadequate information needed in projects. This paper aims to explore the implementation of LOD in projects using BIM in the construction industry. In order to do so, the definition, purposes and content of each level of LOD had been identified based on past literature. In addition, semi-structured interviews were conducted with BIM consultants from the public and private sector. The findings revealed that the implementation of LOD is varied depending on the requirements of construction players. From the use of LOD, it helps construction players to get the information that they need for a specific purpose in various project phases. The use of LOD in projects using BIM shows the capability and the level of understanding of construction players in using BIM.
\end{abstract}

\section{Introduction}

Building Information Modeling (BIM) means replacing 2-dimensional (2D) drawing as an architectural design with 3-dimensional (3D) model [1]. BIM increases project design efficiencies, foster an integrated design workflow and reduce errors in design process [1]. The 3D model for a construction project must be entangled with contextual data-rich building components or elements. All information regarding contextual data-rich building elements were mainly referred from level of development (LOD) specification [1].

The LOD concept is introduced in BIM to enable construction players in the Architecture, Engineering and Construction (AEC) industry to specify and articulate with a high level of content clarity as well as reliability of the 3D models at various stages [2]. LOD is associated with Level of Detail [1]. Level of Detail is the amount of details included in the building model elements [2,3,4]. On the other hand, LOD is the degree to which the element's geometry and related information regarding the components have been thought by construction players when using the model $[2,3]$. It means that LOD is the degree to which project team members could rely on the information while using the model. In essence, Level of Detail is an input to the element, while LOD defines reliable output $[2,5,6]$.

LOD is used to cover several issues that happen in the design stage [7,8]. This is because, it is easy to misinterpret the precision of an element to be modeled [2,6]. Added to that, there is a need to differentiate the amount of information of building model elements [2,6]. Furthermore, it allows model users to define the use of the building models, as well as to allow construction players to clearly understand the usability and the limitations of the received building models. 
There are five levels of LOD, which consist of LOD 100, LOD 200, LOD 300, LOD 400 and LOD 500. These levels are covered from conceptual to as-built and facility management $[2,6]$. The information on each LOD characteristic is shown in Figure 1.

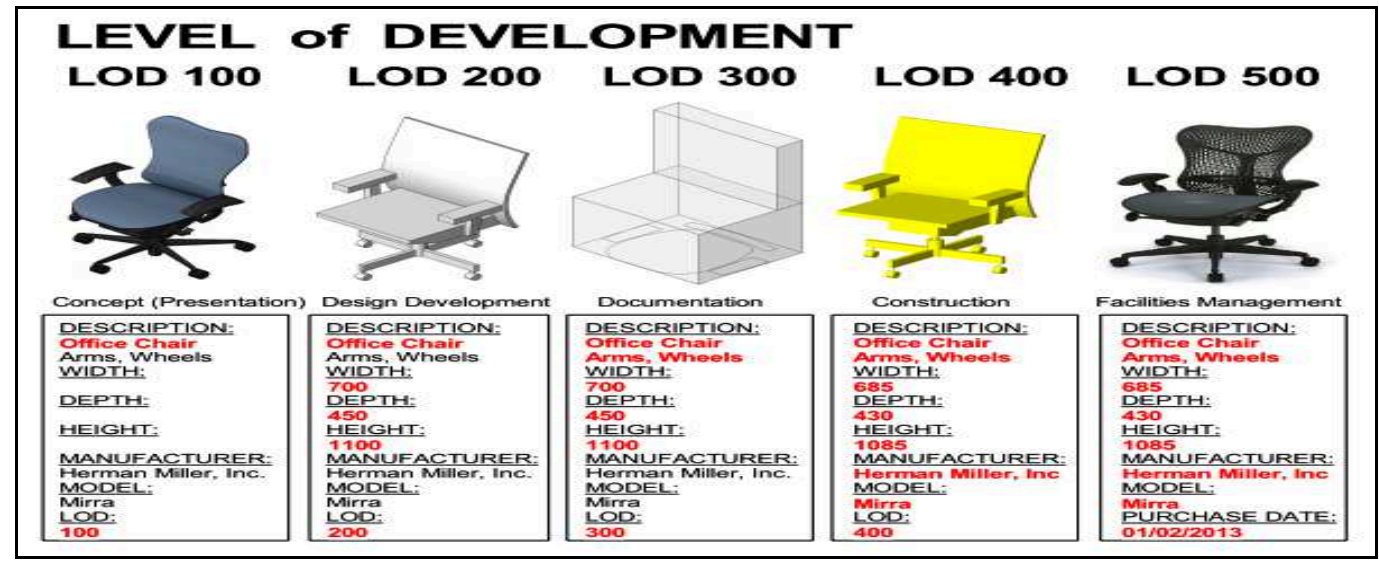

Fig. 1, The Level of Development (LOD) [7]

Based Fig. 1, each level represents specific content requirements, authorized use of the model as well as specific purpose of the model $[3,8,9,10]$. LOD 100 is a conceptual level $[2,3,6,8]$. The model elements is represented graphically in a symbol $[2,3]$. The information in LOD 100 is not much and usually used for project pre-planning, feasibility studies and basic cost estimation [3]. From the development of LOD 100, it can derive other information for LOD 200 such as width, depth, height as well as the manufacturer of the product [2].

LOD 200 is a design development of a product $[2,6,11]$. The building model elements in LOD 200 are represented as generic systems, object with accurate quantity, size, shape, location as well as the orientation of the product $[2,3,6]$. At this level, performance analysis could be conducted to determine which building model elements to be used [2]. The next level of LOD is LOD 300 where it is on the documentation of a product $[6,12,13]$. Apart from that, LOD 300 also consists of a nongraphic information such as estimating and scheduling. Moreover, LOD 300 is more precise in terms of their quantity, size, shape, location as well as orientation as it is defined by the client [3]. Specific details on the performance aspect of the components may be added with necessary information defined by client in order to develop construction documents [3]. From LOD 300, it can develop detailed information for LOD 400 which is a fabrication of elements.

LOD 400 is compatible with the construction of the product and more suitable for fabricators and contractors $[3,12,13]$. It is because the model elements in LOD 400 are represented as a specific system and object that consist detailing of orientation, fabrication and installation information. Lastly, LOD 500 is represented as as-built model that consists of information needed in facility management $[3,6]$. LOD 500 could be considered as a fully accurate digital representation of a manufactured product [2].

Moreover, there is also a specification of LOD 350 [3]. LOD 350 is used to develop coordination between any disciplines such as clash detection $[3,6,11]$. The use of LOD is varied according to country as well as construction players, which depends on the scope and requirements of work [3, $11,12,13,14]$. Therefore, the LOD in construction project using BIM will be explored in this paper. The next section discusses the methodology for this research.

\section{Methodology}

Two methods were used in order to obtain information regarding LOD in Malaysian construction projects. The first method was based on past literatures to explore on the definition of LOD and it purposes. The information is gathered from journal articles, books and materials available on the internet. Then, semi-structured interviews were conducted with several consultants from public 
sector and private sector. The purpose of the interview is to understand respondents' experience on BIM and LOD in the construction industry. Data obtained from the interviews were recorded and transcribed. All the data were analyzed by using content analysis and represented via tables and documents. Content analysis is typically presented as a series of well defined steps that take analysis from the initial identification of research questions and construct to the final interpretation of the data [15].

\section{Results and Findings}

This part is divided into three (3) sections, which are respondents' background, understanding on BIM and LOD, and the extent of LOD usage in construction projects.

\section{Respondents' Background}

There are four (4) respondents involved in the semi-structured interview. Two (2) respondents are representative of the public sector and the other two (2) are from the private sector. All respondents have experiences in implementing BIM in construction projects. The respondents from the public sector are senior assistant director in architecture and structural departments. Meanwhile, the respondents from the private sector are BIM principal director and executive of innovation. Table 1 shows the respondents' background. The respondents is coded as R1 to R4 to be further discussed.

Table 1. Respondents' Background

\begin{tabular}{|c|l|l|c|}
\hline Respondent & Category & \multicolumn{1}{|c|}{ Position } & Experience using BIM [Year] \\
\hline R1 & Public sector & Senior Assistant Director & 4 \\
\hline R2 & Public sector & Senior Assistant Director & 4 \\
\hline R3 & Private sector & BIM Principal Director & 8 \\
\hline R4 & Private sector & Executive of Innovation & 5 \\
\hline
\end{tabular}

The roles of R1 and R2 are monitoring construction projects, prepare project designs and consultation on behalf of client. R1 and R2 have experiences in managing project using BIM for 4 years. Meanwhile, the roles of R3 are to prepare and coordinate project designs by using BIM tools. R3 has experiences with BIM for 8 years. The roles of R4 are to monitor and enhance BIM implementation among consultant and contractor, which cooperate with R4 company. R4 also involves with Research and Development (R\&D) on BIM. R4 has experiences with BIM for 5 years.

\section{Understanding on BIM and LOD}

$\mathrm{R} 1$ and R2 agreed that, BIM is a new process in managing project designs, which involves a set of parametric model and the model must be analyzed. Meanwhile, R3 and R4 agreed that BIM is pleasant and expedite process of managing construction projects which involves people, process, technology and policy. The uses of BIM in construction project life cycle have involved a group of construction players (client, architect, structural engineer, mechanical and electrical (M\&E) engineer, quantity surveyor and contractor) in order to manage construction projects.

All respondents agreed that the advancement of technology in producing BIM tools such as Revit (architecture, structural, M\&E and Navisworks) allow construction players to analyze project design through 3D parametric models. R3 and R4 agreed that in order to implement BIM in construction projects, it is important to understand what is BIM and its processes before it can be implemented in the projects. According to all respondents, BIM process consists of different types of LOD. R4 stated that each type of LOD have different levels of fuctionality in term of its specific contents of development and purposes of the model. Table 2 shows the understanding on BIM and LOD. 
Table 2. Understanding on BIM and LOD

\begin{tabular}{|c|c|c|}
\hline Respondent & Understanding on BIM & Understanding on LOD \\
\hline $\mathrm{R} 1$ & $\begin{array}{l}\text { BIM is a process, which involves } 3 \mathrm{D} \text { parametric } \\
\text { components and must be analyzed. }\end{array}$ & $\begin{array}{l}\text { LOD is the detailed component in project design } \\
\text { which includes information such as specification } \\
\text { and dimension. }\end{array}$ \\
\hline R2 & $\begin{array}{l}\text { BIM is a new method or process to execute or } \\
\text { develop design by using parametric model. }\end{array}$ & $\begin{array}{l}\text { LOD is a specific component used in project } \\
\text { design. }\end{array}$ \\
\hline R3 & $\begin{array}{l}\text { BIM is a process of managing construction } \\
\text { projects, which involves people, process, } \\
\text { technology and policy. }\end{array}$ & LOD is all about project design detailing. \\
\hline R4 & $\begin{array}{l}\text { BIM is a pleasant and expedite process in } \\
\text { managing construction projects. }\end{array}$ & $\begin{array}{l}\text { LOD is a part of BIM process, which consists of } \\
\text { LOD 100, LOD 200, LOD 300, LOD } 400 \text { and } \\
\text { LOD 500. Each LOD consists different level of } \\
\text { development in design process. }\end{array}$ \\
\hline
\end{tabular}

\section{The Extent of LOD Usage in Construction Projects}

All respondents explained that LOD consists of LOD 100, LOD 200, LOD 300, LOD 400, and LOD 500. All respondents also agreed that LOD 100 is essentially equivalent to conceptual design and LOD 200 is similar to schematic design. Furthermore, LOD 300 is extended to construction document and LOD 400 is fabrication drawing. LOD 500 according to all respondents represent the as-built drawing, which is facility management (FM) information.

All respondents stated that, LOD is a part of BIM process. The use of LOD depends on client requirement and it must be determined during the early stage of project. R1 and R2 stated that two (2) of their commercial building projects have extended to LOD 300. However, R1 and R2 also targeted that both projects will be extended to LOD 500 for the purpose of FM. R2 explained that, the contractor for both projects will produce all information required in LOD 500 to client.

Apart from that, R3 explained that most of his projects especially commercial building projects have used LOD 300. Moreover, R3 has used LOD 500 for the purpose of FM for one of his commercial building project. The project, according to R3 did not use BIM in the early stage of construction. The client has proposed to use LOD 500 for the purpose of FM after completion of the project.

R4 stated that most of his projects, which is residential project were extended to LOD 300 . R4 will determine the extension of LOD earlier in the project execution plan (PEP) for other construction players. PEP is developed in the early stage of a project to identify the appropriate project goal and project process [16]. R4 mentioned that all information in PEP are important for execution of construction projects and it should be stated as one of the conditions in the contract of the project as a proof of client requirement on LOD in the project. Therefore, construction players need to fulfill all the conditions stated in PEP.

\section{Conclusion and Further Works}

The enhancement of BIM can be seen through the use of LOD in construction projects. The extent of LOD in construction projects show the level of BIM understanding and ability of the construction players in managing construction projects using BIM. The utilization of LOD in public sector has achieved LOD 300, meanwhile, private sector has achieved LOD 500 in projects using BIM. It revealed that the implementation of BIM in the Malaysian construction industry had been preceded by the private sector.

The use of LOD in BIM process shows the maturity of the construction players in managing projects using BIM. Further works is needed to identify BIM practices in many projects using BIM in the Malaysian construction industry. More interviews with other construction players involved in projects using BIM can be conducted to identify the extent of LOD usage in projects using BIM. 


\section{Acknowledgement}

The authors would like to thank the Ministry of Education of Malaysia (MOE), and the Office of Research, Innovation, Commercialization and Consultancy (ORICC), UTHM, for supporting this research under the Exploratory Research Grant Scheme (ERGS), Vote No. E029.

\section{References}

[1] F. Levy. BIM in small-scale sustainable design, John Wiley \& Sons, Inc. 2012.

[2] American Institute of Architects (AIA), Level of Development Specification for Building Information Model. Information on http://bimforum.org/wp-content/uploads/2013/08/2013-LODSpecification.pdf.

[3] R.S. Weygant. BIM Content Development, John Wiley \& Sons, Inc. 2011.

[4] F. Leite, A. Akcamete, B. Akinci, G. Atasoy, and S. Kiziltas, Analysis of Modeling Effort and Impact of Different Levels of Detail in Building Information Models. Automation in Construction, 20 Vol. 5. (2011). 601-609.

[5] P. E. Love, I. Simpson, A. Hill, and C, Standing. From Justification to Evaluation: Building Information Modeling for Asset Owners. Automation in Construction, Vol. 35, (2013). 208-216.

[6] K. P. Reddy, BIM for Building Owners and Developers. John Wiley \& Sons, Inc. New Jersey. 2012.

[7] Practical BIM, Information on http://practicalbim.blogspot.com/2013/03/what-is-this-thingcalled-lod.html.

[8] A. Porwal, and K. N. Hewage, Building Information Modeling (BIM) Partnering Framework for Public Construction Projects. Automation in Construction, Vol 31. (2013). 204-214.

[9] Autodesk, Inc. Autodesk BIM Deployment Plan: A Practical Framework for Implementing BIM. Information on http://www.akcb.com/attachments/BIM_Deployment_Plan_Final.pdf.

[10] Cleveland Clinic, Cleveland Clinic-BIM Implementation Plan. Information on http://portals.clevelandclinic.org/Portals/57/20130814\%20Cleveland $\% 20$ Clinic $\% 20 \%$ E2\%80\%93\% 20BIM\%20Implementation\%20Plan\%20R1.1.pdf.

[11] C. Agar, BIM Plan: Level of Development. Information on http://www.bimmepaus.com.au/libraries/resources/BMA\%20Forum\%202012/bim\%2020level\%20o f\%20detail.pdf.

[12] C. Eastman, P. Teicholz, F. Sacks, and K. Liston, BIM Handbook: A Guide to Building Information Modeling. John Wiley \& Sons. Inc. New Jersey. 2011.

[13]L.A.H.M. Van Berlo and F. Bomhof, Creating the Dutch National BIM Levels of Development. In Computing in Civil and Building Engineering. (2014). 129-136.

[14]J. Bedrick, A Level of Development Specification for BIM Process. Information on http://www.aecbytes.com/viewpoint/2013/issue_68.html.

[15] K. Klenke, Qualitative Research in the Study of Leardership. Emerald Group Publishing Limited. 2008.

[16] A. Akintoye, J. Goulding, and G. Zawdie, Construction Innovation and Process Improvement. Blackwell Publishing, Ltd. 2012. 